\title{
Production of binderless activated carbon monoliths by KOH activation of carbon mesophase materials
}

\author{
J.M. Ramos-Fernández, M. Martínez-Escandell, F. Rodriguez-Reinoso \\ Dept. Química Inorgánica, Universidad de Alicante, Apartado 99, E-3080 Alicante, Spain
}

Activated carbons (AC) prepared from mesophase-based materials usually possess high surface area and micropore volume, making them adequate for adsorption, catalysis and gas or energy storage. Chemical activation with $\mathrm{KOH}$ or $\mathrm{NaOH}$ is one of the most common methods to produce these materials $[1,2]$, usually as a fine powder $[3,4]$, thus making its conforming to pellets or monoliths an important area of research. The manufacture of monoliths normally involves the use of a binder, which implies a reduction of porosity due to partial blocking, the extent of which depends on the kind and proportion of binder used $[3,4]$. As mesophase-based materials have self-sintering ability, these materials are good candidates to produce monoliths of activated carbon of high surface area without using a binder, but no success has been reported up to now [5]. This paper reports the use of mesophase pitch (MP) and mesophase self-sintering carbon (MSC) for the synthesis of activated carbon monoliths (ACM) with high consistency and large porosity, without the need for a binder.

For the preparation of the MP a petroleum residue (ethylene-tar) [6] was pyrolyzed in a laboratory pilot plant at $440^{\circ} \mathrm{C}$ and a pressure of $1.0 \mathrm{MPa}$, using a heating rate of $10^{\circ} \mathrm{C} / \mathrm{min}$ and a soak time from 2 to 4 hours. MSC was the solid obtained after extraction of the MP with THF at its boiling point.

The synthesis of the ACMs involved several steps: i) mixture of the MP or MSC with $\mathrm{KOH}$ in a ball mill during 30 minutes; ii) uniaxial conforming at room temperature to produce monoliths $(25 \times 25 \times 5 \mathrm{~mm})$, conforming pressure varying from 100 to $400 \mathrm{MPa}$ (the mixture of the carbon

\footnotetext{
•Corresponding Author. Fax: 3496590 3454. E-mail adress: manolo.m@ua.es (M.Martínez Escandell)
} 
precursors and the activating agent can be consolidated because of its high plasticity); iii) heat treatment at $800^{\circ} \mathrm{C}$ under nitrogen atmosphere, soak time of $2 \mathrm{~h}$ and heating rate of $2^{\circ} \mathrm{C} / \mathrm{min}$; and iv) washing of monoliths with a solution of $1 \mathrm{M} \mathrm{HCl}$, followed by extensive washing with distilled water until $\mathrm{pH}=7$. The final step consists on drying of the monolith at $100-110^{\circ} \mathrm{C}$ for 24 hour. Bulk densities of the monoliths were determined by measuring the dimensions of the samples and their dry weight.

Table 1 summarises the characterization of some of the precursors studied in order to achieve ACMs with good mechanical resistance coupled with high surface area. The low ash content of the MP and MPC has to be pointed out, ash being mainly composed by $\mathrm{Si}, \mathrm{Al}, \mathrm{Fe}$ and $\mathrm{Ca}$. For the first screening, the activation was carried out using a $\mathrm{KOH} /$ carbon ratio of 2 for all samples. The first activation tests were carried out using MSCs. This kind of material has the highest mesophase and carbon content, coupled with low volatile matter, but it also exhibits the highest softening point and viscosity upon melting of all tested materials. All the monoliths produced with this precursor had low consistency and could not be manipulated without breaking down to a powder, thus indicating that sintering of the grains had not been sufficient. Forming was varied from 100 to $400 \mathrm{MPa}$ but results did not change much. It seems that fusibility of MSC samples is not large enough to allow an extensive reduction of inter-particular space and to impart sufficient mechanical strength to the monoliths.

Table 1: Characterization of some of the mesophase pitches and mesophase self-sintering carbons

\begin{tabular}{ccccccccc}
\hline Sample & Conditions & $\begin{array}{c}\text { TI } \\
(\%)\end{array}$ & $\begin{array}{c}\text { NMPI } \\
(\%)\end{array}$ & $\begin{array}{c}\text { Mesophase } \\
\text { content }(\%)\end{array}$ & $\begin{array}{c}\mathrm{C} / \mathrm{H}_{\text {at }} \\
\text { Carbon Yield } \\
(\text { wt } \%)\end{array}$ & $\begin{array}{c}\text { Softening } \\
\text { point }\left({ }^{\circ} \mathrm{C}\right)\end{array}$ & $\begin{array}{c}\text { Ash } \\
\text { content } \\
(\text { wt } \%)\end{array}$ \\
\hline MP-2 & $440^{\circ} \mathrm{C}-1 \mathrm{MPa} / 2 \mathrm{~h}$ & 52 & 33 & 42 & 1.68 & 68 & 140 & 0.012 \\
MP-4 & $440^{\circ} \mathrm{C}-1 \mathrm{MPa} / 4 \mathrm{~h}$ & 62 & 50 & 65 & 1.78 & 74 & 200 & 0.010 \\
MSC-2 & MP-2 extracted THF & 90 & 77 & 60 & 2.03 & 87 & 260 & 0.017 \\
MSC-4 & MP-4 extracted THF & 92 & 82 & 70 & 2.05 & 88 & 325 & 0.015 \\
\hline
\end{tabular}

Notes. TI, Toluene insoluble content; NMPI, N-methyl-2pyrrolidone insoluble content; $\mathrm{C} / \mathrm{Hat}, \mathrm{C} / \mathrm{H}$ atomic ratio; Softening Point (TMA determination) 
The use of MP was not originally considered to be the best option as the carbon yield of the material after pyrolysis was much lower; however, the preliminary results were better than for MSC. It seems that the lower softening point and viscosity of the MP as compared to the MSC is very important to bind the carbon grains, despite the presence of $\mathrm{KOH}$, this being the key of this new process. The results indicate that the carbonization soaking time used to produce the original MP (2-4 h) does not seem to affect the sinterability of their mixtures with $\mathrm{KOH}$, the final ACMs exhibiting similar consistency. One could expect an improvement of the ACM (higher density) when increasing the carbonization soak time to produce the MP, due to the higher mesophase content, $\mathrm{C} / \mathrm{Hat}$ ratio and carbon content of the MP. However, it seems that there is a compensation effect leading to similar properties, which may be originated by the higher softening point and viscosity of the pitch. On the other hand, the forming pressure was more important for consistency than the carbonization soak time. For instance, the samples conformed at 100-200 $\mathrm{MPa}$, broke down during the washing step or had low consistency, whereas the 400MPa monoliths were hard and did not undergo any weight loss along manipulation. Concerning the range studied here, the best conditions to prepare the monoliths were selected as follows: four hours pyrolysis soaking time, as it gives the highest carbon yield and 400MPa forming pressure, as it yields the largest consistency.

Using these previous optimised conditions to prepare the $\mathrm{ACM}$, the effect of $\mathrm{KOH} / \mathrm{carbon}$ ratio on the porous texture has also been studied, the nomenclature of $A C M$ indicating the ratio $\mathrm{KOH} / \mathrm{C}$ (ACM-1, ACM-2, ACM-3 and ACM-4) used. Ash content of the ACMs was lower than $0.01 \mathrm{wt} \%$, lower than in the starting MP. The ACMs were characterised by adsorption of $\mathrm{N}_{2}$ at $77 \mathrm{~K}$ and $\mathrm{CO}_{2}$ at $273 \mathrm{~K}$. The corresponding $\mathrm{N}_{2}(77 \mathrm{~K})$ adsorption isotherms, plotted in Figure 1, are of Type I, with a well defined plateau, thus indicating that these materials are essentially microporous. The shape of the knee between 0 and 0.2 relative pressure indicates that the micropore size distribution becomes broader for the samples with increasing $\mathrm{KOH} / \mathrm{C}$ ratio. 


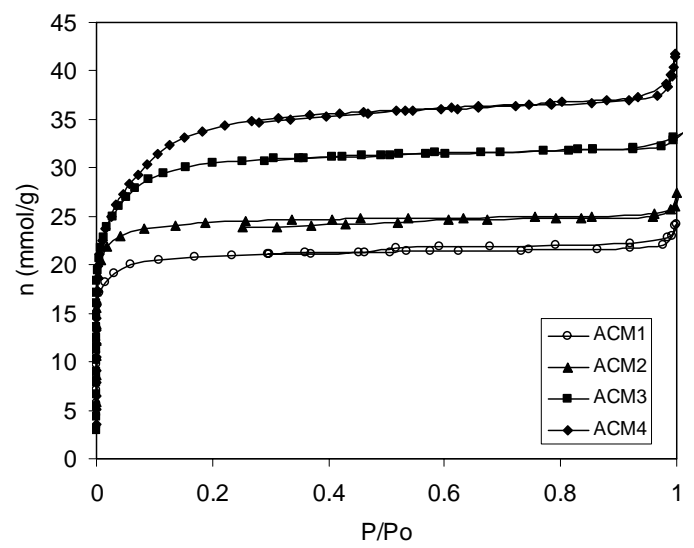

Figure 1. $\mathrm{N}_{2}$ Adsorption isotherms at $77^{\circ} \mathrm{K}$.

The BET equation was applied to $\mathrm{N}_{2}$ adsorption isotherms from which an "apparent" or "equivalent" BET area was obtained (the area equivalent to extend the volume adsorbed at the calculated theoretical monolayer) because of the microporous nature of the samples. The apparent surface area increases with $\mathrm{KOH}$ activation, reaching values up to $2850 \mathrm{~m}^{2} / \mathrm{g}$ (Figure 2).

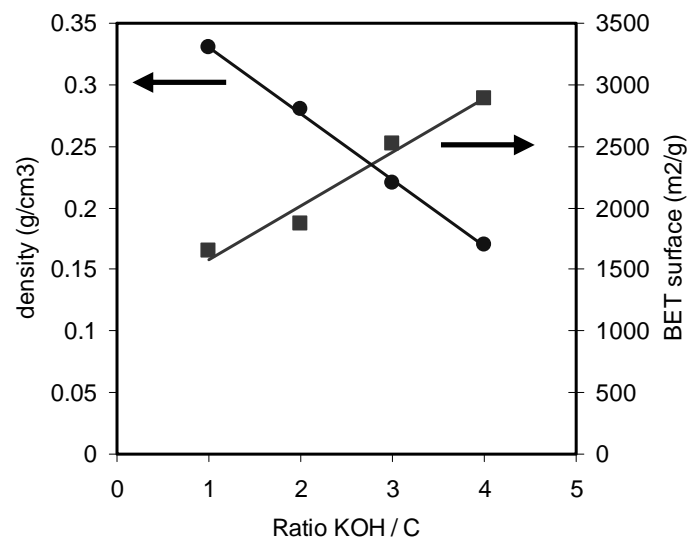

Figure 2. Evolution of bulk density and BET surface with $\mathrm{KOH} / \mathrm{C}$ ratio

The bulk density is reduced as a result of the increase in the porosity of the materials (Figure 2). This reduction in density is mainly induced by the porosity generated by the activation process itself, but it is also produced by the existence of inter-particle spaces left behind after the removal of the chemicals produced during activation $\left(\mathrm{K}_{2} \mathrm{O}, \mathrm{K}, \mathrm{K}_{2} \mathrm{CO}_{3}\right.$, etc). 
The Dubinin-Radushkevich (DR) equation was applied to the $\mathrm{N}_{2}(77 \mathrm{~K})$ and $\mathrm{CO}_{2}(273 \mathrm{~K})$ isotherms to obtain the total micropore volume $\left(\mathrm{V}_{\mathrm{N} 2}\right)$ and the volume of narrow micropores $\left(\mathrm{V}_{\mathrm{CO} 2}\right)$ [7]. The mesopore volume was obtained by difference between the volume measured at $P / P_{0}=0.95$ and the micropore volume $\left(\mathrm{V}_{\mathrm{N} 2}\right)$. The materials are mainly microporous, the micropore volumen increasing with $\mathrm{KOH} /$ carbon ratio (Figure 3) and reaching values up to $1 \mathrm{~cm} 3 / \mathrm{g}$.

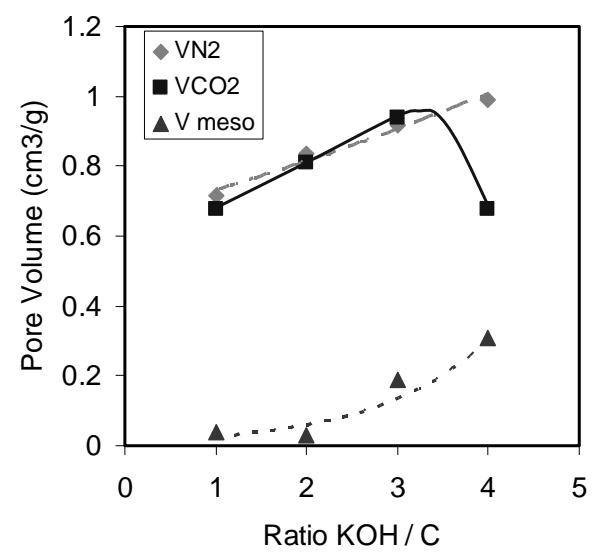

Figure 3. Evolution of the micropore volume deduced from adsorption of $\mathrm{N}_{2}\left(\mathrm{~V}_{\mathrm{N} 2}\right)$ and $\mathrm{CO}_{2}\left(\mathrm{~V}_{\mathrm{CO} 2}\right)$, and mesopore volume $\left(\mathrm{V}_{\text {meso }}\right)$, as a function of $\mathrm{KOH} / \mathrm{C}$ ratio

Most of this microporosity is narrow, as differences between $\mathrm{N}_{2}$ and $\mathrm{CO}_{2}$ curves are only observed for the largest $\mathrm{KOH} /$ carbon ratio, when micropores become wider [7]. The volume of mesopores is not large but it increases with the $\mathrm{KOH} / \mathrm{C}$ ratio up to $24 \%$ of total porosity.

When analysing the microstructure of a transversal cut of the monolith by SEM (Figure 4), a continuous mass can be observed, where no grain boundaries can be distinguished. The existence of voids of several tens of microns, which may have formed in the boundaries of the grains, are responsible for the relatively low density of the monoliths (but this density is large in respect to the typical carbon powders produced by $\mathrm{KOH}$ activation). 


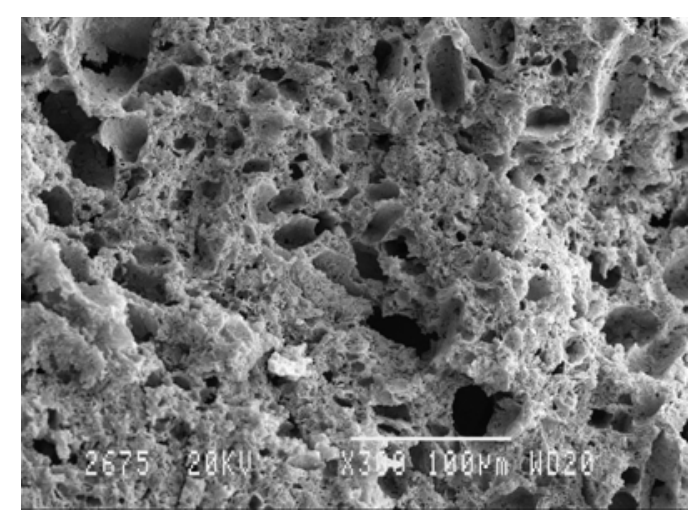

Figure 4. SEM image of a transversal cut of ACM-3 monolith

In conclusion, a new method for preparation of binderless activated carbon monoliths has been established, in which the high selfsinterability of the mesophase-based material has been used to sinter the powder, yielding consistent monoliths with up to $2800 \mathrm{~m}^{2} / \mathrm{g}$ apparent surface area. The analysis of the porosity of the monoliths indicates that they are essentially microporous, reaching micropore volumes up to $1 \mathrm{~cm}^{3} / \mathrm{g}$, but mesoporosity can be as large as $24 \%$ of the pore volume, exhibiting additionally some interparticle voids. This porous texture (large amount of microporosity with high accessibility due the interparticle voids) may be important for many advanced applications such as supercapacitors.

\section{References}

[1] Marsh H, Yan DS, O'Grady TM, Wennerberg A. Formation of active carbons from cokes using potassium hydroxide. Carbon 1984; 22(6): 603-11.

[2] Berger D, Carton B, Métrot A. Interaction of potassium and sodium with carbons. In: Thrower PA, Walker PL, Jr, editors. Chemistry and Physics of Carbon, vol. 12. New York; Marcel Dekker, 1975:1-36.

[3] Ubago-Pérez R, Carrasco-Marín F, Fairén-Jiménez D, Moreno-Castilla C. Granular and monolithic activated carbons from $\mathrm{KOH}$-activation of olive stone. Microporous and mesoporous materials 2006; 92:64-70. 
[4 Lozano-Castelló D, Cazorla-Amoros D, Linares-Solano A, Quinn D.F. Activated carbon monoliths for methane storage: influence of binder. Carbon 2002; 40: 2817-25.

[5] Molina-Sabio M., Rodríguez-Reinoso F., Colloids and surfaces: A physicochemical Eng. Aspects 2004; 241:15-25

[6] Torregrosa-Rodríguez P, Martínez-Escandell M, Rodríguez-Reinoso F, Marsh H, Gómez de Salazar C, Romero Palazón E. Pyrolysis of petroleum residues: Il. Chemistry of pyrolysis. Carbon 2000; 38:535-546.

[7] Rodríguez-Reinoso F, Garrido J, Martín-Martínez JM, Molina-Sabio M, Torregrosa R. The combined use of different approaches in the characterization of microporous carbons. Carbon 1989; 29: 23-32.

\section{Acknowledgements}

Support from the Ministerio de Educación y Ciencia (project MAT2004-03480-C02-02) and the European Union (Network of Excellence Insidepores, NMP3-CT-2004-500895) are acknowledged. 